\title{
Geospatial Analysis and Research on Social and Spatial Inequality of Compulsory Education: A Case Study of Hangzhou, China
}

\author{
Ge He $\mathbb{D}^{1}$ and Qinshi Huang $\mathbb{D}^{1,2}$ \\ ${ }^{1}$ School of Architecture and Urban Planning, Nanjing University, Nanjing 210093, China \\ ${ }^{2}$ School of Civil Engineering and Architecture, Zhejiang University of Science and Technology, Hangzhou 310023, China
}

Correspondence should be addressed to Qinshi Huang; huangqinshi@zust.edu.cn

Received 10 May 2021; Accepted 23 August 2021; Published 31 August 2021

Academic Editor: Jing-Hu Pan

Copyright (C) $2021 \mathrm{Ge} H e$ and Qinshi Huang. This is an open access article distributed under the Creative Commons Attribution License, which permits unrestricted use, distribution, and reproduction in any medium, provided the original work is properly cited.

\begin{abstract}
Equal compulsory education is an important way to realize social and spatial equality, while the uneven allocation of educational resources in different regions and groups results in inequality of opportunity and solidification of social strata. Traditional research conducted on the basis of fixed search range ignores the special institutional background of Chinese school district system. In this paper, an improved Gaussian two-step floating catchment area model is developed taking into consideration the school district system, while the bivariate local spatial analysis method and geographically weighted regression model are employed to study the social and spatial differentiation of compulsory education accessibility and its capitalization effects in Hangzhou. Results show that (1) the improved Gaussian two-step floating catchment area model is more in line with the national condition of China's "nearby schooling" policy; (2) the accessibility of compulsory schools in Hangzhou shows an obvious core-periphery typology, and the aggregation effect of primary school accessibility is more significant than that of secondary schools; (3) compared to groups with high socioeconomic status, vulnerable groups are highly disadvantaged in terms of access to educational services; (4) spatial heterogeneity exists in education capitalization, and the areas where education accessibility has the strongest impact on housing prices are in the central city with rich high-quality educational resources; (5) high-quality educational resources, highpriced communities, clusters of high socioeconomic status groups, and communities enjoying high-level education accessibility are highly consistent in all spaces, which is the spatial expression of educational inequality. The research on Hangzhou, a regional central city, provides a theoretical basis and technical support for the humanistic shift in the allocation of educational resources.
\end{abstract}

\section{Introduction}

As economic globalization and neoliberalism advance, the gap between rich and poor has widened drastically. Given that differences in individual family background and ability endowments naturally exist and are difficult to eliminate, it is a top priority for the country's education efforts to rationalize the allocation of educational resources through the process of spatial redistribution and to alleviate educational inequality caused by unequal social and economic status. Education is an important manifestation of social governance and the degree of justice as it forms the foundation of people's livelihood. Hence, educational equality has a direct impact on the quality of people's lives. However, issues with imbalance and inadequacy in China's education remain prominent, which may lead to significant social problems such as class consolidation. Because of the scarcity of educational resources and differentiation of local government's economic strength, there are extensive regional, urban-rural, and interschool differences in the allocation of educational resources $[1,2]$. Since educational resources directly determine students' performance and play a decisive role in their future career choices [3-5], differences in the allocation of educational resources highlight the key role of education in the production and reproduction of identity by social groups $[6,7]$. Groups with high socioeconomic status (SES) 
are able to use endogenous attributes such as economy, culture, and social capital to achieve monopoly on quality educational resources [8]. Subsequently, future generations who enjoy quality educational services can further consolidate their social status. This kind of intraclass identity transmission, brought about by the differentiation of educational resource allocation, ensures the continuity of upperclass social status and cuts off the possibility of upward mobility of the bottom masses, intensifying social differentiation and stratification.

Accurately assessing the service capacity of educational resources is a prerequisite for exploring educational inequality. Since Hansen proposed the concept of accessibility [9], scholars use various spatial and temporal methods to quantitatively analyze the differences in spatial accessibility of educational facilities [10-18]. These models, without exception, determine whether residents are located within the service area by artificially delineating service thresholds for educational facilities $[12,17,19]$. However, unlike the compulsory education system in Western countries, China's "nearby schooling" policy has set an aspatial threshold for access to educational services $[11,20]$, and the service capacity of educational resources cannot be measured simply by how easy it is to reach the nearest school from a given location. In fact, under the school district system, social attributes are attached to educational facilities. These are essentially geographically distributed public goods, making the measurement of accessibility and equity more complex. The "nearby schooling" policy does not refer to the nearest school in terms of space but the right given to all school-age teenagers to attend schools within their registered household region. Therefore, ignoring the role of school district when calculating accessibility of education will enlarge the error $[14,21]$. Accordingly, combining factors such as school location, service quality, and school district constraints, we define education accessibility in the Chinese context as the ability of a population to obtain services from a school which he or she is allowed to attend.

A correct understanding of the relationship between the difference among groups and educational accessibility is the key to grasping the connotation of educational equality and promoting it. Traditionally, educational equality has been about ensuring all students enjoy equal access to education. However, educational equality cannot simply be equated to equal education opportunities. Value judgments need to be made on the distribution process and relative results about whether they are reasonable and good, since the equity of distribution results or status does not necessarily mean equality. In fact, the difficulty in accessing public goods and services varies significantly among groups with different backgrounds, economic capabilities, and social status. Existing research points out that low-income groups [22], migrants [23], racial/ethnic minorities [24, 25], and other vulnerable groups are usually disadvantaged in terms of access to public services [26-28]. When investigating educational equality, we should not only concentrate on "place prosperity" but also pay attention to "people prosperity" $[29,30]$. Educational equality is to achieve equal educational opportunities based on individual differences. When it comes to the index of accessibility, it should not only include the geographical barriers that people overcome to access public services in the physical world but also take into consideration social factors such as individuals' class, status, and reputation [31, 32]. Most prior studies in China equate educational equity with education equality and treat the equal allocation of educational resources as a criterion, whose focus is geographical justice rather than demographically targeted equality [21, 33]. With increasing awareness of social problems, a few researchers focused on exposing social inequality by exploring the differences in the ability of various social groups to access quality educational services [34-36]. Few scholars have assessed the quality of educational services through quantitative methods from the perspective of social equality [37]. Only by matching education accessibility with different social groups and accurately identifying the status of individuals enjoying highquality education services, we can allocate educational resources in a targeted manner and realize "people prosperity," which will lead us to the ultimate goal of equal education.

As the basic unit of access to educational services, housing, which has both the geographical attribute of immovability and the social attribute of providing people with living space and corresponding eligibility for admission, provides us with another perspective to connect geographic territory and society [38]. The nature of housing as a commodity enables residents to pursue high-level educational resources by housing purchase $[39,40]$. Because of the scarcity of school district housing, the value of the public attribute of education accessibility is inevitably capitalized through the surrounding housing [41, 42], which leads to a filtering mechanism for groups that cannot afford the premium of high-quality educational resources $[43,44]$ and exacerbating social stratification and socio-spatial inequality. Accurately identifying the degree of capitalization of education accessibility is critical to understanding the mechanism by which inequitable allocation of educational resources causes social problems. This will aid governments in deciding the structure of educational supply as well as the direction of educational policy reform.

As such, this research breaks through the limitations of traditional accessibility measurements and integrates the complex characteristics of spatial accessibility, service comprehensiveness, and access threshold of educational resources. It measures the equity of educational resource allocation from various aspects such as spatial distribution and social group matching, while exploring the capitalization effect of education accessibility with a view to gain insights into education, housing, and urban development policy making.

\section{Study Area and Data}

2.1. Study Area. Hangzhou, the capital of Zhejiang Province, is one of the most populated cities situated in the Yangtze River Delta. It is also one of the political, economic, and cultural centers of southeast coastal China. The chosen study area is the area around the city highway which is regarded as the main city, while public primary and secondary schools as 
well as residential communities are selected as subjects for analysis. The study mainly covers administrative districts including Shangcheng, Xiacheng, and Binjiang, most of Xihu, Gongshu, and Jianggan, and parts of Xiaoshan and Yuhang, covering a total area of about $1,040.41 \mathrm{~km}^{2}$ (Figure 1).

Although Hangzhou has always been at the forefront of basic education across the whole country, the distribution of its educational resources is still differentiated where key primary and secondary schools are generally located in areas closer to the city center. Compared to regular primary and secondary schools, the educational resources of the schools in the inner city are more abundant. Consequently, the educational equality in the periphery of the city is greatly reduced, and construction and allocation of educational resources in related areas are still in progress. Given that private schools do not recruit students based on school districts, their impact on surrounding communities over a short time is negligible. Therefore, public primary and secondary schools in the main city are taken as research subjects.

2.2. Data. Data of school districts came from the List of School District Scope of Public Primary and Secondary Schools published by Hangzhou Municipal Education Bureau in 2020. There are 303 public schools within the study area, including 210 primary schools and 93 secondary schools.

As primary schools do not hold entrance examinations into secondary schools in Hangzhou, there are no official data on the ranking of primary schools. Operationally, we formed the hierarchy of all primary schools based on ranking information provided by local real estate agency websites such as Fangtianxia.com and 51souxue.com and random interviews with second-hand housing transaction platforms. Among 210 primary schools, prestigious schools generally recognized by the public with good reputation are assigned a value of 4 , prestigious schools with a certain influence are assigned a value of 3 , schools with limited influence are assigned a value of 2 , and other schools are assigned a value of 1 .
Unlike Western countries, although the examinations to enter high schools can reflect the quality of secondary schools in China, the data published by various schools have different calibers and some schools do not publicize relevant data [45]. Consequently, this article uses the enrolment rate of top eight senior high schools (also known as "best eight") as the basis, combined with the evaluation given by local real estate agency, to classify 90 secondary schools. Several other Chinese scholars adopted similar methods and treated enrolment data combined with social subjective opinions as an indicator of school quality [46]. Also, some Western studies utilized similar methods and obtained robust estimation results [47, 48]. Similar to the assignment mechanism of primary school, secondary schools with better reputation are given higher scores.

The housing price data are collected from the list offered by Hangzhou Real Estate Market Comprehensive Management Service Center and supplemented with information from China Housing Price Quotes Platform (http://creprice. $\mathrm{cn})$ in 2020. The demographic and social characteristics of the streets come from the results of the sixth census in Hangzhou, in 2010. The longitude and latitude of primary and secondary schools, school districts, and residential communities are generated by Google Earth. Geographic elements such as study area, traffic road networks, water systems, and mountains are vectorized using ArcGIS to establish a spatial database in the study area.

2.3. Method. As an improved model of two-step floating catchment area (2SFCA) method, the Gaussian two-step floating catchment area (G2SFCA) method is widely used to analyze spatiotemporal accessibility since it emphasizes the fact that residents' demand for public goods will decrease with distance. Among most impedance functions, Gaussian decay function, rather than exponential function or power function, can best describe the supply-demand relationship between residents and the park that is normally distributed with distance $[49,50]$. This allows G2SFCA to more realistically calculate accessibility under the influence of distance.

As the name suggests, the classic G2SFCA method is composed of two steps as follows:

$$
\begin{aligned}
R_{j} & =\frac{S_{j}}{\sum_{k \in\left\{d_{k j} \leq d_{0}\right\}} G\left(d_{k j}, d_{0}\right) N_{k}}, \\
A_{i} & =\sum_{i \in\left\{d_{i j} \leq d_{0}\right\}} G\left(d_{k j}, d_{0}\right) R_{j}, G\left(d_{k j}, d_{0}\right)= \begin{cases}\frac{e^{-(1 / 2) \times\left(d_{k j} / d_{0}\right)^{2}-e^{-(1 / 2)}}}{1-e^{-(1 / 2)}}, & d_{k j} \leq d_{0}, \\
0, & d_{k j} \leq d_{0},\end{cases}
\end{aligned}
$$

where $R_{j}$ is the supply-demand ratio of the facility $j, S_{j}$ means the supply capacity of facility, $N_{k}$ indicates the sum of the population of each demand point $k$ within a threshold distance $\left(d_{0}\right)$ from $j, A_{i}$ is the accessibility of each demand point $i$, and $G\left(d_{i j}, d_{0}\right)$ means the Gaussian distance between $i$ and $j$ while $d_{i j}$ is the geographic distance between $i$ and $j$. 

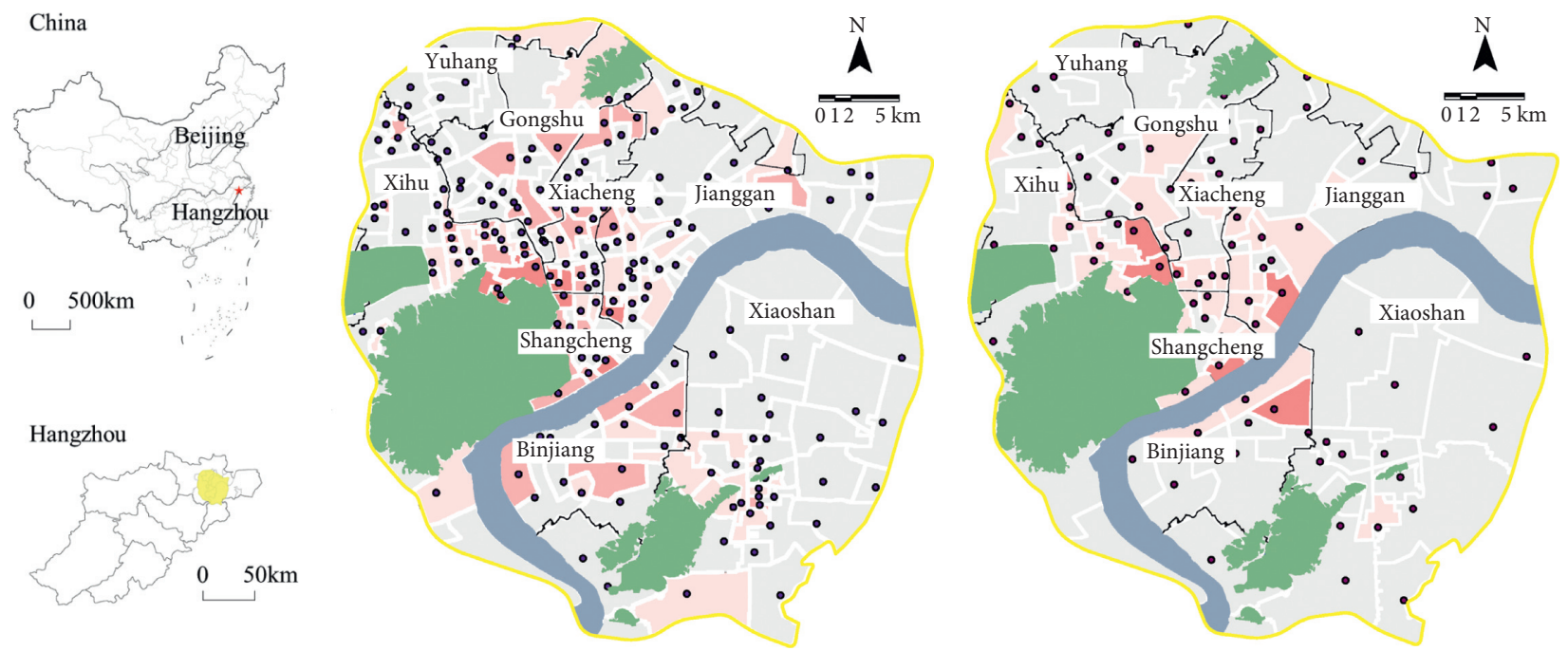

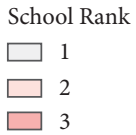

(a)

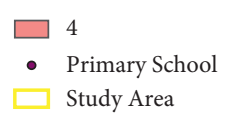

(b)

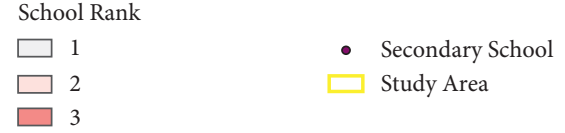

(c)

FIGURE 1: Study area and subject. (a) Location of the study area. (b) Distribution of primary schools and school districts. (c) Distribution of secondary schools and school districts.

However, there are several aspects that can be improved. Facility capacity is represented by a single index in most studies, which is not accurate enough. On the other hand, under school district policy, it is not the distance between the supply point and demand point that decides which gets the right to enjoy the service. To improve the accuracy of the model, we modified the correlation coefficient of the supply and demand relationship of public primary and secondary school.

(1) We enriched the indicator of the supply capacity (i.e., school service quality) to make sure the school's hardware and software facilities and residents' needs will not be missed out. According to current standards [51], there are several indexes that should be combined to inspect service capacity. We selected school level $l$, area $a$, number of teachers $t$, and number of students enrolled in 2020 se to measure the performance of each school. (2) Before delineating the service area according to the distance threshold of the supply point and selecting the serviceable demand point, it is necessary to establish a collection of communities that can be served by particular school according to the delimited school district. Since every community in a certain school's district can enjoy educational service no matter how far it is to the school in spatial aspect, $d_{0}$ is decided by the distance from the farthest community. The advanced G2SFCA formula is listed as follows:

$$
\begin{aligned}
R_{j}^{\prime} & =\frac{S_{j}^{\prime}}{\sum_{k \in T_{j}} G\left(d_{k j}, d_{\max }\right) N_{k}}, \\
A_{i}^{\prime} & =\sum_{i \in T_{j}} G\left(d_{k j}, d_{\max }\right) R_{j}^{\prime},
\end{aligned}
$$

$$
S_{j}^{\prime}=l \times\left(w_{1} \times\left(a \times a_{0}\right)+w_{2} \times\left(t \times t_{0}\right)+w_{3} \times s e\right),
$$

where $T_{j}$ refers to the collection of all communities in the school $j$ 's district. $d_{\max }$ is the distance between the school $j$ and the farthest community in its district. In equation (4), $a_{0}$ is the official standard for area per student while $t_{0}$ means the official standard for teachers. $w_{1}, w_{2}$, and $w_{3}$ are the weights of school area, number of teachers, and number of students. According to relevant studies, teacher quality shows a stronger relationship than school facilities to pupil achievement [52], which enables a school with more teachers to provide better service. Besides, the number of students enrolled directly determines the school's ability to absorb and serve school-age children. Therefore, it was decided that $w_{1}=0.2, w_{2}=0.4$, and $w_{3}=0.4$.

In order to march towards "people prosperity," a spatial correlation analysis of the education accessibility among different groups characterized by socioeconomic attributes was added based on census data. In this level of research, the study area was divided into $500 \mathrm{~m} \times 500 \mathrm{~m}$ grid adding up to 3,793 grids in total. We assigned accessibility data and census data to our grids based on their location. The Bivariate Local Indicator of Spatial Association (biLISA) method $[53,54]$ is employed to identify the spatial agglomeration characteristics of the supply capacity of public primary and secondary schools and the demand levels of different social groups, followed by exploring the matching degree between the two. The calculation formula of biLISA is

$$
I_{x y}^{m}=z_{x}^{m} \sum_{n} W_{m n} z_{y}^{n}
$$


where $z_{x}^{m}$ represents the standardized value of education accessibility at grid $m$ and $z_{y}^{n}$ stands for the value at grid $n$. $W_{m n}$ is the spatial weight matrix between $m$ and $n . I_{x y}^{m}$ refers to the linear correlation between the variable value $z_{x}^{m}$ at grid $m$ and the mean value $z_{y}^{n}$ of another variable at the surrounding research unit $n$.

To explore the average effect of education accessibility on housing prices, we employed geographically weighted regression (GWR) to investigate the spatial heterogeneity and detect the spatial pattern of the impact of educational resource quality on housing prices. The model is as follows:

$$
P_{b}=\beta_{0}\left(u_{b}, v_{b}\right)+\sum_{c=1}^{q} \beta_{c}\left(u_{b}, v_{b}\right) f_{b c}+\varepsilon_{b},
$$

where $P_{b}$ is the housing price of residential community $b$, $\left(u_{b}, v_{b}\right)$ is the spatial location coordinates of $b, \beta_{c}\left(u_{b}, v_{b}\right)$ represents the $c$-th regression parameter at $b, f_{b c}$ represents the coefficient value of the $c$-th variable at observation point $b$, and $\varepsilon_{b}$ is the random error.

Housing prices are affected by various factors, most of which are measured by hedonic attributes. According to existing studies, hedonic determinants include architecture attributes (basic functions of a house such as age, decoration, and greening rate), location attributes (distance to the city center, metro station or landscape etc.), and neighborhood attributes (such as schools, hospitals, and parks in the surrounding area). Taking into account the availability of relevant data, we separate accessibility attributes from neighborhood attributes so as to analyze the mechanism of the impact school district has on housing price.

The socioeconomic data involved and their descriptive statistics are shown in Tables 1 and 2. Comparing the rank of education accessibility with the rank of the house price or population, we attempt to identify school deserts for different populations.

\section{Results and Discussion}

3.1. Spatial Distribution of Public Educational Facilities. In recent years, the supply of public education services in Hangzhou has shown a rising trend, which is closely related to economic development and population growth. From 2009 to 2019, the total number of students in school increased by $42.5 \%$ and the number of schools increased by $26.3 \%$ [55]. At present, the level of educational resource supply in Hangzhou is at the forefront of the whole country. The number of public education degrees offered per 10,000 people is 606.7 , far exceeding the national average. The student-to-teacher ratio of primary and secondary schools is $15: 1$ and $12: 1$, which exceeds the standard set by "Opinions on the Establishment of the Standards for the Establishment of Primary and Secondary School Staff" from the Central Editing Office which set them at 19:1 and 13.5:1. However, there are obvious shortcomings in the spatial allocation of educational resources. Several smallest streets own the most concentrated educational resources, which reflects the lack of equity in the allocation of educational resources.
3.2. Accessibility Distribution of Educational Resources. The accessibility of education calculated via improved G2SFCA is shown in Figure 2. On the whole, the distribution shows an obvious core-periphery typology where the accessibility was higher in the center and lower in the surrounding areas. High-value primary schools are mainly clustered in the central area including part of Xihu, Shangcheng, and Xiacheng (in the red circle), which is the inevitable result of high concentration of quality schools and dense road networks. Different from primary school accessibility, there is no obvious high-value cluster relating to secondary schools. Apart from the central group comprising Xihu, Shangcheng, and Xiacheng, there are two other groups showing the same pattern, namely, in Binjiang and Xiaoshan (in the green circle). Inside each group, the accessibility value shows a gradual decrease from the inside to the outside. The reason may be that the dense population had a relatively high demand in the inner city which narrows the gap among regions. In addition, the development stage of the city changed from the "Xihu Era" to the "Qiantang River Era" and the construction of infrastructure is comparable on each side.

When looking into the different characteristics of education accessibility, it was concluded that there are several factors that affected the access to educational services. School quality is the most decisive factor to education accessibility. Communities located in school districts with better reputation and wider recognition generally have higher accessibility, as shown in Figure 2. This relationship is evident and strongly proven in most areas including Xihu and Shangcheng. Quality schools are favored in the process of financial allocation to education and can provide higher level services consequently, which leads to the guaranteed accessibility over average level.

However, there is no absolute connection between the high quality of the school and the high accessibility of school district housing. First, the supply capacity of schools is determined by the quality of school, area, number of teachers, and number of students enrolled. Limited by land supply, campus area in the central city is significantly smaller than that in the suburbs. To control the quality of teaching, elite elementary schools often impose strict restrictions on the number of students enrolled, which weakens the superiority of schools in rankings. As a result, there are some schools topping the list while their demand points face high pressure for access to educational resources. Apart from that, since accessibility is decided by supply, demand, and the gap between them, the higher the demand for the school district, the lower the accessibility of each demand point. The places where residential communities are concentrated have a correspondingly greater demand for educational resources, making local schools incapable of meeting the oversaturated demand for educational services. With too many communities to serve, top schools failed to provide satisfactory amount of educational resources. On the contrary, less demand allows ordinary schools the opportunity to maximize the potential of educational resources.

Distance is not the key factor that affects ease of access to educational facilities since communities in the same district generally have the same level of accessibility. In fact, parents are willing to travel farther for better educational service. 
TABLE 1: Socioeconomic indicators.

\begin{tabular}{|c|c|c|c|}
\hline Variable type & Variables & Explanation & Data source \\
\hline \multirow{4}{*}{$\begin{array}{l}\text { Dependent variable } \\
\text { location }\end{array}$} & Housing price & Data on housing prices & Listing data \\
\hline & Central potential & $\begin{array}{l}\text { The product of the distances to Wulin Square }{ }^{1} \text { and the nearest } \\
\text { secondary commercial center }\end{array}$ & Google Earth \\
\hline & Traffic potential & Distance to the nearest subway station & Google Earth \\
\hline & Landscape potential & Distance to the nearest large-scale landscape resource & Google Earth \\
\hline \multirow{2}{*}{ Architecture } & House age & Year from the completion of house & Listing data \\
\hline & Greening rate & The ratio of green area to the planned area of the community & Listing data \\
\hline \multirow{2}{*}{ Accessibility } & $\begin{array}{l}\text { Accessibility to primary } \\
\text { school }\end{array}$ & Quality of primary school per student & $\begin{array}{l}\text { Calculated } \\
\text { data }\end{array}$ \\
\hline & $\begin{array}{l}\text { Accessibility to secondary } \\
\text { school }\end{array}$ & Quality of secondary school per student & $\begin{array}{l}\text { Calculated } \\
\text { data }\end{array}$ \\
\hline \multirow{6}{*}{ Neighborhood } & Lifestyle facilities & Distance to the nearest shopping mall or supermarket & Google Earth \\
\hline & Medical facilities & $\begin{array}{c}\text { Distance to the nearest hospital, clinic, or community healthcare } \\
\text { center }\end{array}$ & Google Earth \\
\hline & Financial facilities & Distance to the nearest bank branch (not including ATM) & Google Earth \\
\hline & Leisure facilities & $\begin{array}{l}\text { Distance to the nearest park, square, campus, or cultural and sports } \\
\text { facilities }\end{array}$ & Google Earth \\
\hline & F\&B facilities & Distance to nearest restaurant & Google Earth \\
\hline & Business facilities & Distance to the nearest commercial building & Google Earth \\
\hline
\end{tabular}

${ }^{1}$ Wulin Square is recognized to be the city center.

TABle 2: Descriptive statistics of variables.

\begin{tabular}{|c|c|c|c|c|c|}
\hline Variables & Unit & Maximum & Minimum & Mean & Median \\
\hline Housing price & US dollar ${ }^{2}$ & $21,033.67$ & $1,432.46$ & $5,300.65$ & $5,100.51$ \\
\hline Central potential & $\mathrm{km}^{2}$ & $1,377.68$ & 0.34 & 39.84 & 23.48 \\
\hline Traffic potential & $\mathrm{m}$ & $29,331.91$ & 5.81 & $3,044.88$ & $1,784.13$ \\
\hline Landscape potential & $\mathrm{m}$ & $8,626.91$ & 22.31 & $2,188.66$ & $1,814.43$ \\
\hline House age & Years old & 41.00 & 3.00 & 16.06 & 16.00 \\
\hline Greening rate & $\%$ & 75.46 & 10.00 & 30.46 & 30.00 \\
\hline Accessibility to primary school & - & 185.59 & 0.00 & 1.43 & 0.85 \\
\hline Accessibility to secondary school & - & 6.80 & 0.00 & 0.72 & 0.54 \\
\hline Lifestyle facilities & $\mathrm{m}$ & $2,145.22$ & 3.11 & 278.97 & 218.45 \\
\hline Medical facilities & $\mathrm{m}$ & $2,245.79$ & 1.43 & 261.06 & 190.80 \\
\hline Financial facilities & $\mathrm{m}$ & $3,150.78$ & 7.66 & 359.87 & 244.95 \\
\hline Housing price & $\mathrm{m}$ & $3,859.43$ & 2.49 & 484.54 & 373.22 \\
\hline Central potential & $\mathrm{m}$ & $1,372.29$ & 1.24 & 134.41 & 107.80 \\
\hline Traffic potential & $\mathrm{m}$ & $8,921.95$ & 9.13 & $1,118.31$ & 776.98 \\
\hline
\end{tabular}

${ }^{2}$ According to IRS, yearly average exchange rates for converting Chinese yuan into US dollars in 2020 is RMB6.900 : US\$1: https://www.irs.gov/individuals/ international-taxpayers/yearly-average-currency-exchange-rates.

Figure 3 shows the mapping results and the geographic distribution of accessibility calculated by the classic G2SFCA method which does not coincide with reality. Zhuantang Subdistrict in Xihu District and the area along the river in Binjiang District (in the red circle) display the highest accessibility. However, these areas do not have abundant highquality educational resources and the population density is relatively high, which means that the surrounding communities do not have the potential to enjoy access to highquality education. The reason why education accessibility in the central city is underestimated is that the radius of school district in the central area is much smaller than 2,000 meters. When calculating with traditional methods, demand points that are out of the school district are also taken into consideration, which leads to nonexistent competition among irrelevant demand points. As a result, the corresponding education accessibility is unsatisfactory since the needs of residents are incorrectly identified. For the same reason, education accessibility in periphery areas is overestimated. Hence, it is important in the analysis of education accessibility to decide the number of demand points according to the scope of the school district. This will minimize the overor underestimation of demand under current school district system in China.

3.3. Spatial Heterogeneity of Education Accessibility. In order to evaluate the spatial pattern between education accessibility and socioeconomic characteristics, we analyzed the mapped spatial distribution of five variables, namely, the presence of migrants, residents with rural hukou (China's hukou system is a family registration program that serves as a domestic passport, regulating population distribution and rural-to-urban migration; 

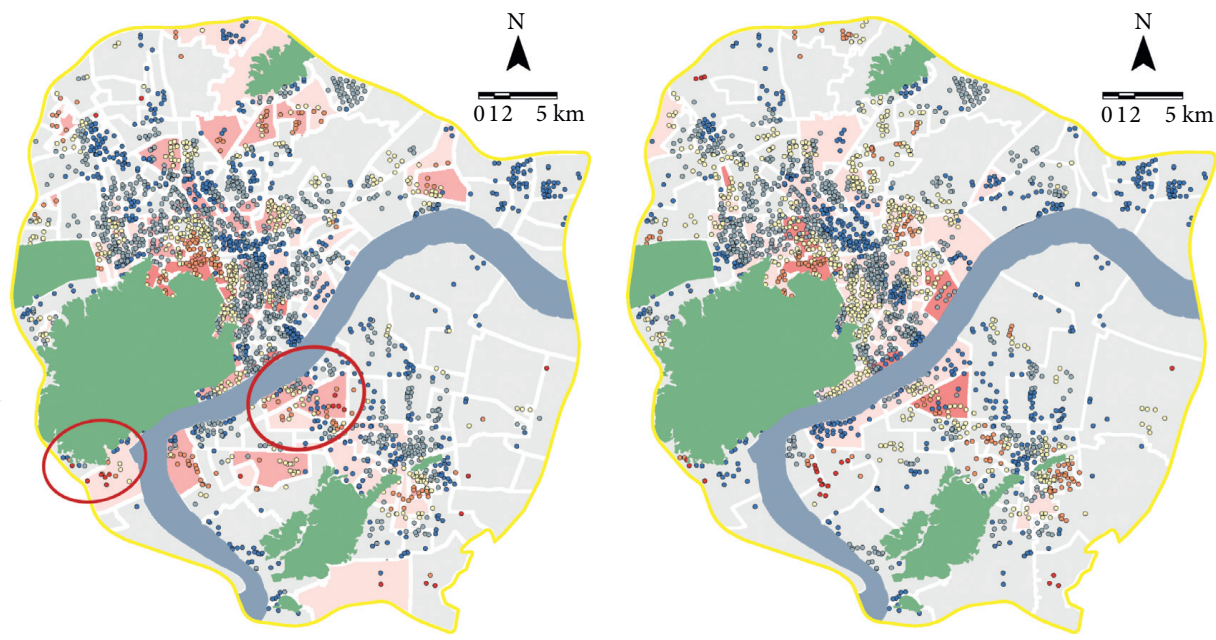

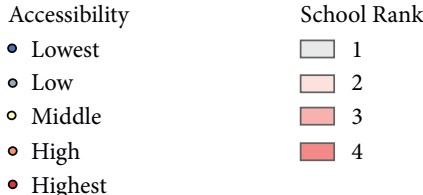

(a)

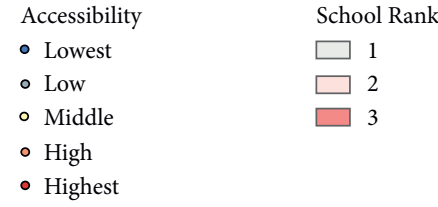

(b)

FIgURE 2: The distribution of education accessibility in Hangzhou with improved G2SFCA. (a) Primary school. (b) Secondary school.
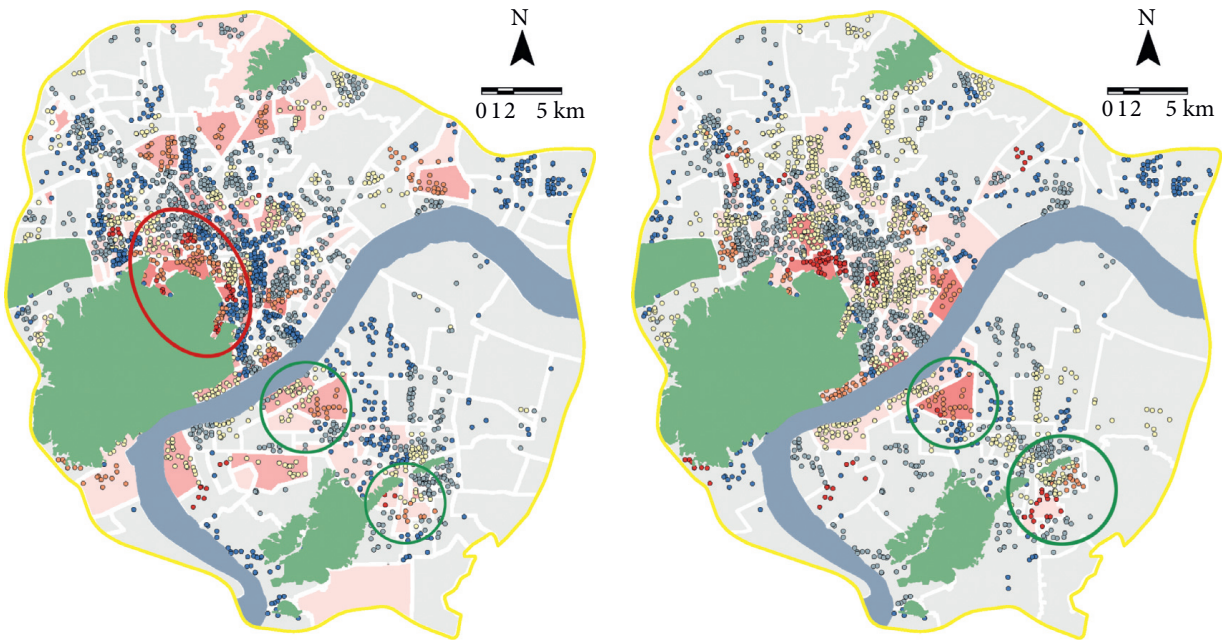

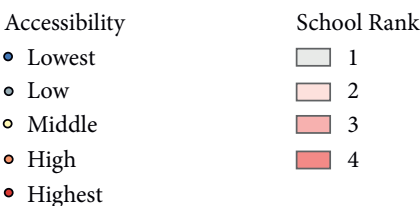

(a)

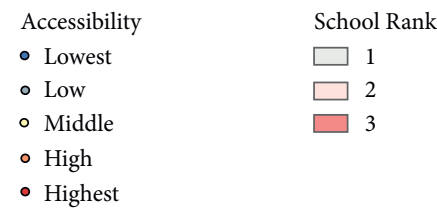

(b)

FIgURe 3: The distribution of education accessibility in Hangzhou with classic G2SFCA. (a) Primary school. (b) Secondary school.

residents with rural hukou are denied from the same rights and benefits enjoyed by urban residents), civil servants, professional technical personnel, and housing price (as an indicator for income). Figure 4 displays the spatial clustering of socioeconomic indicators and the distribution of education accessibility. According to the results of biLISA, the social spatial differentiation pattern of education accessibility is closely related to the characteristics of social groups. High percentages of different groups and high rates of education accessibility show a state of coupling or mismatch depending on the socioeconomic status of the group. 


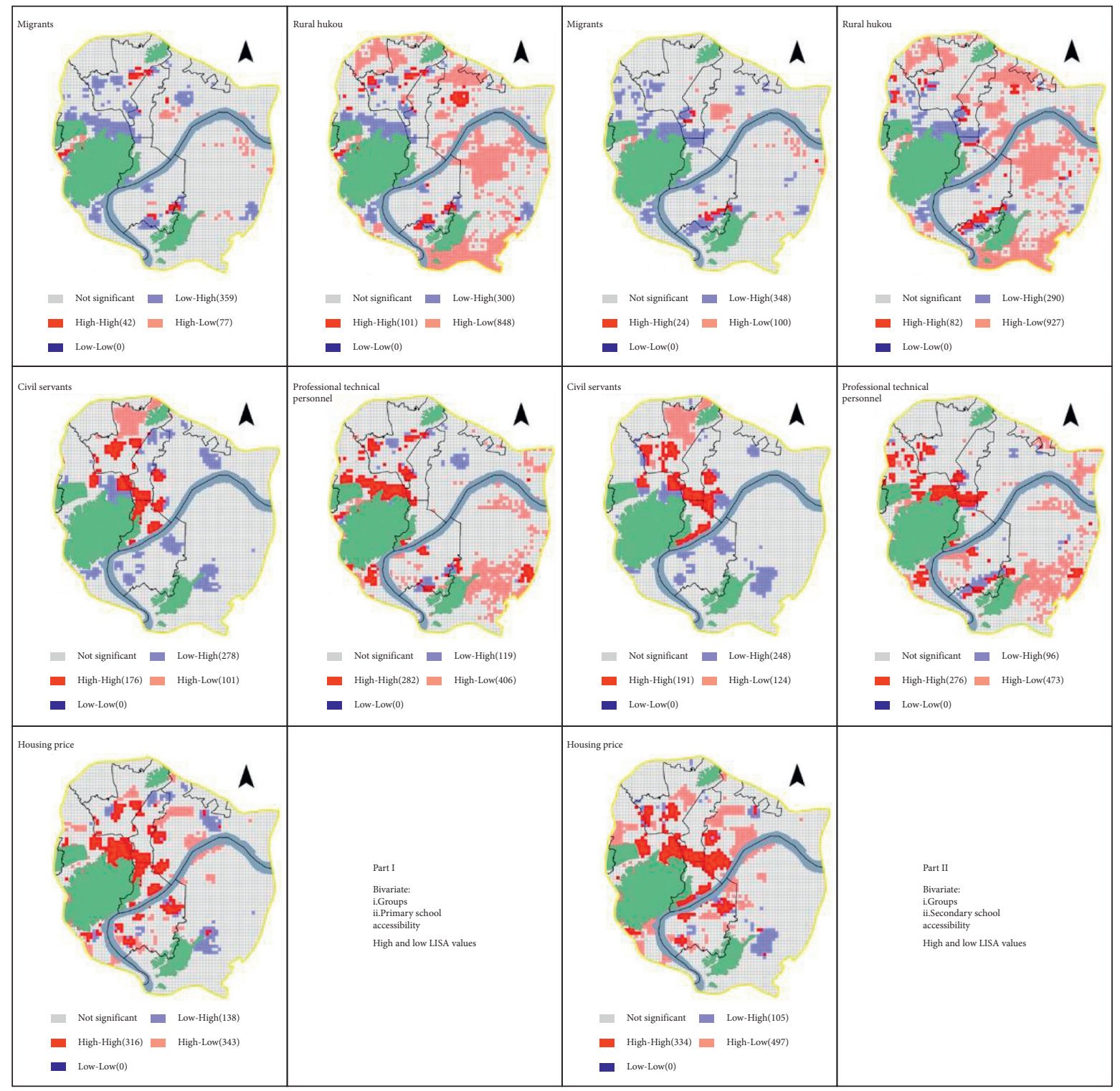

FIgURE 4: LISA high and low cluster of education accessibility among different groups.

Vulnerable groups such as migrants and residents with rural hukou lack sufficient political power to influence the allocation of primary and secondary schools or strong economic power to actively seek high-quality educational resources. Although the government has been carrying out construction of high-level teaching structures (such as the Three-Year Action Plan for Building a Better Education in Hangzhou), the beneficiaries are only limited to parents who can afford a house in the city center.

Out of consideration to reduce rental costs, migrants are more inclined to live in the suburban new city with convenient public transport [56]. Therefore, areas with a high presence of migrants are mainly located in Gongshu and the vicinity of the ring road. This phenomenon of spatial mismatch between educational resources and groups has resulted in rather few migrants who can meet their education needs, and the total number of migrants who cannot is far less than the migrants who can. Residents with rural hukou are more widely distributed in the periphery of the investigated area where education accessibility is lower. The concentration of rural hukou in the periphery of the city such as Gongshu and Xiaoshan is particularly obvious, where the area is vast and there are still a large number of rural and village committees except for the well-developed streets. However, compared to these places, city center is favoured for its high population density when the local government builds new educational facilities. As a result, migrant residents can hardly meet their needs for high-level education services.

An analysis done on education accessibility on socioeconomic status showed that the middle class has absolute upper hand in the competition for high-quality educational resources. This is specifically expressed by the high degree of spatial coupling among high SES groups, high-quality educational resources, and high-level education accessibility. Similar to the research results from studies conducted in 
Sweden and France, groups with low socioeconomic status have a higher degree of inequality in educational opportunity [57].

In terms of occupation, areas with highly educated individuals, such as civil servants, teaching and research personnel, and professional technical personnel, are consistent with the range of high-quality school districts. A possible explanation for this outcome could be that there is still an invisible system that prioritizes quality educational resources for formerly respected and established occupations, namely, employees of government and institution, despite the dissolution of "unit system" under the influence of market economy. Under the situation where schools have limited supply capacity, the scope of school district was forced to shrink, and only nonemployees with strong financial capabilities are able to access these renowned schools.

As for income, housing price can partly represent income level since areas with high housing prices usually have higher concentration of high-income groups. According to the results from biLISA analysis, the distribution of education accessibility presents significant spatial heterogeneity among high- and low-income groups. Most areas with high housing prices and high levels of education accessibility are located in the central city with well-developed transportation systems and rich educational resources. The results suggest that high-income groups have completed the monopoly of high-quality educational resources through the filtering effect of the real estate market and housing purchases. Areas with less access to educational services and high housing price are scattered around the central area where landscape resources are rich, the potential explanation to which is that citizens who choose these areas are not attracted by teaching resources but other city services.

Unlike vulnerable groups, the middle class who enjoys high education accessibility has an overwhelming advantage over the disadvantaged middle class that does not. Under active parental choices, the middle class generally has good education accessibility and the stratification of middle class school districts has already occurred. High-quality educational resources guarantee that housing in the surrounding district enjoys above-average levels of education accessibility, which attracts high SES groups who are willing and capable to fight for better educational services for their children. The high SES groups will gather near renowned schools. This housing filtering mechanism forms educationdriven residential spatial differentiation, which has a great impact on the social structure within the school district.

The distribution of access to secondary schools is heterogeneous and shows certain mismatch while education services failed to reach more groups. This can be explained by the changes in supply and demand during the process of calculation. Secondary school districts are larger, and the number of demand points in each district has doubled. Therefore, the pressure on each school to provide more quality education resources has increased, and the level of access enjoyed by each demand point has decreased significantly. At the same time, larger school district means families have to travel further to seek educational services, which leads to an increase in the average commuting distance from the community to the school, further weakening the school's service capacity. This downward trend is not obvious when accessibility of secondary schools is analyzed separately. However, when it is combined with the social characteristics of the group, the spatial differentiation is accurately captured. The matching attributes of biLISA analysis can not only describe the degree of spatial differentiation but also improve accuracy when identifying mismatches that are ignored by single-item analysis.

\subsection{Capitalization Effect of School Quality on Housing Price.} GWR is applied to explore the spatial heterogeneity of educational capitalization. Before GWR is conducted, the ordinary least squares (OLS) regression is needed to identify insignificant factors. Ultimately, there are eleven factors, i.e., accessibility to primary school, accessibility to secondary school, greening rate, central potential, traffic potential, landscape potential, lifestyle facilities, medical facilities, recreational facilities, F\&B facilities, and business facilities. The adjusted $R^{2}$ of the model is 0.508 , indicating that the socioeconomic factors chosen can partially explain housing prices. We focus on the impact of educational resources on housing prices and try to portray the capitalization effect of school quality on housing prices.

Figure 5 depicts the coefficient distribution of various urban services. The regression coefficients of primary school accessibility are mostly positive in the study area (Figure 5(a)), indicating that homebuyers are willing to pay a certain premium to live near a primary school, which is consist with Song's conclusion [58]. The coefficient distribution of accessibility to primary schools is evidently regular. The quality of primary schools has a strong and positive influence on housing prices. The regression coefficient manifested a radial distribution, with areas with better educational resources, namely, the junction of Shangcheng, Xiacheng, and Xihu (in red circle), displayed the highest value. Areas with poorer educational resources and lower housing prices, namely, center of Binjiang, Xiaoshan, and Jianggan and peripheral areas of Xihu and Gongshu, have become clusters with high negative values.

The average value of the regression coefficient of the accessibility to secondary school increased from 0.08 to 0.11 , indicating that the impact of secondary school on housing prices is greater. The highest capitalization rate appears in the junction of Xihu and Gongshu (in red circle in Figure 5(b)) where there are high-quality secondary schools as well as many high-quality primary education resources, making it the center of high-quality "double school districts" in Hangzhou. Because of the scarcity of high-quality dual school districts, houses in dual school districts tend to be occupied for a long time and the turnover rate is low [21]. The quality of educational resources rather than community characteristics such as building age and community environment and its location becomes the key factor that influences housing prices. After the promulgation of the second-child policy, young parents are more inclined to choose dual-school-district housing under the consideration 


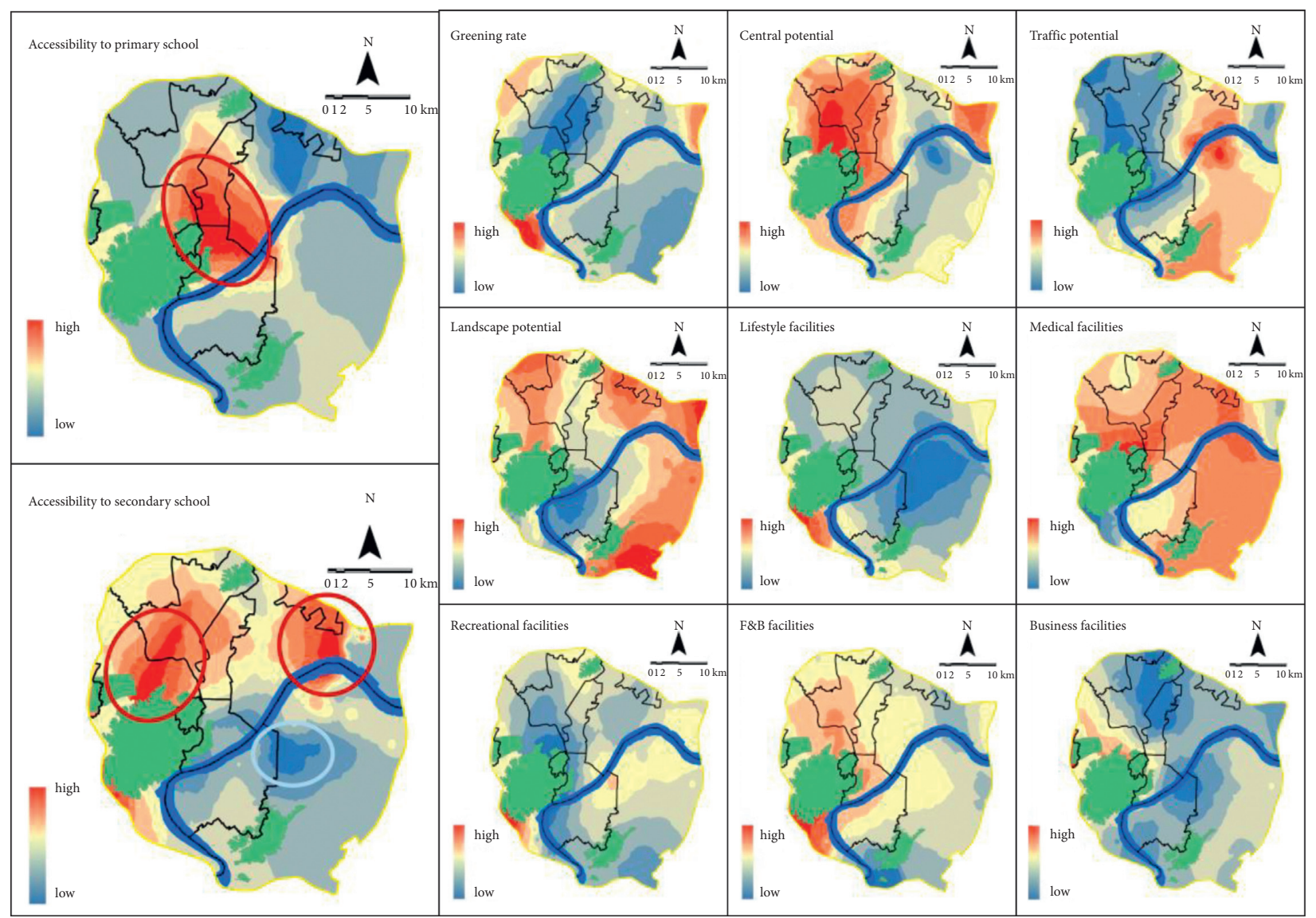

FIGURE 5: Spatial distribution of regression coefficient from the perspective of education accessibility based on the GWR model.

of the convenience in the primary-secondary examination, which leads to the increase of housing prices. Furthermore, the capitalization effect gradually decreased from the city center to the northwest and southeast regions, where relatively high-quality educational resources can be found. Areas with low regression coefficient are located along the Yangtze River and Xiaoshan District (in the blue circle). The housing prices in the relevant areas are slightly affected by secondary school accessibility and are more related to the housing conditions, the location of the community, and the abundance of surrounding supporting facilities, which indicates that the capitalization of educational resources is not thorough.

Given the differences in the natural attributes, social needs, and many other factors, compulsory primary and secondary education resources have significantly different impact on housing prices. Although secondary school has a stronger influence on housing prices in the investigated areas, the scope was reduced. In addition, the standard deviation of the regression coefficient of secondary school accessibility exceeds that of primary school accessibility, indicating that the difference in the impact of secondary school on housing prices in different regions has a trend of expanding. Unlike primary schools, high-quality secondary school access has a greater effect on the improvement of college entrance examination scores and is more likely to be sought after by parents. Therefore, the value-added effect of most ordinary secondary schools on housing prices is limited. However, the pursuit of housing with access to the secondary school superimposed with high-quality primary schools solidified the distribution pattern of the educational resources and expanded the degree of differentiation, which would result in the continuous increase of the positive impact of quality educational resources on housing prices.

\subsection{Educational Inequality under the School District System.} The original intent of the "nearby schooling" policy is to eliminate the phenomenon of school selection by students' score, family background, and their social relationship under the circumstances that differences in educational resources exist objectively and are difficult to eliminate in the short term. Furthermore, the purpose is to weaken the impact of family background on the access to educational opportunities, thereby achieving educational equality. The approach of controlling school choice coincides with the studies on educational equality conducted in European and American countries [59].

However, the implementation of linking educational resources with market-oriented housing has enabled the school district system to create a bidding market for highquality educational resources through "school district housing" transactions, indirectly raising the threshold of school choice. Powerful family background still guarantees 


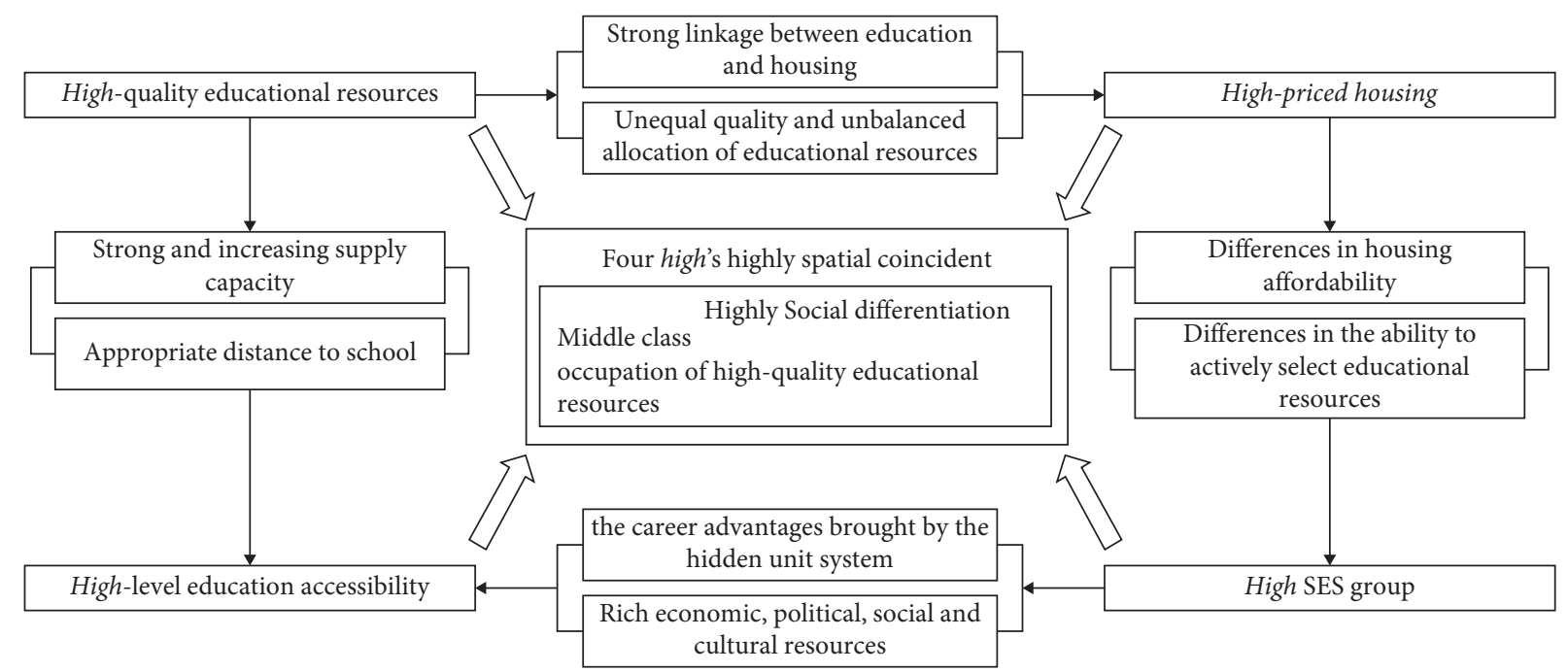

FIgURE 6: Social spatial differentiation and the mechanism of educational resource quality.

the residents an overwhelming advantage in obtaining quality educational resources with the existence of the giant gap among groups in their SES in China. In order to compete for scarce high-quality public educational resources for their children, the wealthy middle class is competing to purchase "school district housing" and thus forming clusters in highquality school districts. This kind of gentrification triggered by the school-choosing behavior of the middle class as the core driving force guarantees the intergenerational transformation and transmission of economic capital, social capital, and cultural capital of wealthy families, but it may also cause social issues such as educational inequality and social spatial heterogeneity.

The mechanism of educational inequality and social mobility problems caused by differences in educational resources under the school district system is as follows (Figure 6): high-quality educational resources ensure the highlevel education accessibility of school district housing and attract parents to obtain high-quality educational services by purchasing school district housing. However, because of uneven quality and unbalanced allocation of educational resources, parents' competition for school district housing directly raises housing prices near high-quality educational resources under the market economy system. Because of the filtering effect of the real estate market, groups with high SES can use endogenous attributes such as finances, culture, and social capital to pursue high-level education accessibility and high-quality educational resources, whereas low-income groups lose opportunities to enjoy quality education and gain subsequent ability to choose careers since they cannot afford high housing prices. The spatial expression of this screening mechanism is that high-quality educational resources, highpriced communities, clusters of high socioeconomic status groups, and communities enjoying high-level education accessibility are highly consistent. Societal performance is that the middle class has completed the occupation of high-quality educational resources, and the disadvantaged groups are confined to the margins and bottom of society, resulting in the increased differentiation of social classes.
School district housing under the "nearby schooling" policy is a direct result of the differences in urban educational resources. The competition for quality school district housing has evolved into a competition of political, economic, social, and cultural strength between families, which runs counter to the original policy intentions and the concept of educational equality. If left unchecked, scarce high-quality educational resources will continue to gather in urban centers and to the upper class. As a result, ordinary families will fall into the vicious cycle of being unable to obtain high-quality educational services and improve their ability to seek high-income jobs to improve their family's economic situation and obtain quality education services for the next generation, losing possible opportunities for upward mobility. In view of the deep effect of educational equality in alleviating social differentiation and promoting social mobility, it is necessary to rationally plan the scope of school districts, narrow the interschool gap, enhance the spatial and intergroup balance in the allocation of educational resources, and make every effort to achieve educational equality.

\section{Conclusions}

Based on the particularity of the compulsory education resource supply pattern under the school district system, this research proposes an improved Gaussian two-step floating catchment area method, which measures the difficulty of obtaining educational services and its social effects from both social and spatial aspects and draws the following conclusions:

(1) Different from the classic G2SFCA method, which uses the distance threshold $d_{0}$ as the standard for the service scope of the supply facilities, the improved G2SFCA method is more in line with China's "nearby schooling" policy which determines enrolment qualifications by the school district. Consequently, the improved G2SFCA method we propose 
that incorporates school district effect into traditional models can provide a more realistic appraisal of accessibility.

(2) In developed coastal areas, the distribution of education accessibility shows an obvious core-periphery typology, and the aggregation effect of primary school accessibility is more significant than that of secondary schools. In terms of the factors that are decisive to education accessibility, school level plays the most important role in determining the level of regional accessibility. High-quality school districts allow the community to enjoy above-average educational services. However, given that high-quality schools are usually accompanied with limited number of student enrolment and competition subsequently gets more intense, there is no doubt that high quality does not guarantee high accessibility.

(3) In the process of rapid urbanization, compared with groups with high socioeconomic status, vulnerable groups in inflow areas are highly disadvantaged in terms of access to educational services. Lacking sufficient political power and strong economic capability prevents migrants and residents with rural hukou from enjoying quality education, whereas groups with high SES gather in the school district through housing purchases and complete their monopoly on quality educational resources, indicating that the phenomenon of stratification in school districts has occurred.

(4) The accessibility to primary schools and secondary schools has significant impacts on housing prices where the commercial housing market is mushrooming. Furthermore, spatial heterogeneity exists in educational capitalization. The highest regression coefficients appear in areas with rich high-quality educational resources. As for secondary school accessibility, areas with high values of the regression coefficients are located in the scarce dual school districts, suggesting that parents are willing to pay high housing prices for good schools and residents in different regions may have disparate preferences for quality education. Fully understanding the complex relationship between education resources and housing prices helps the government to tailor education policies to local conditions.

(5) High-quality educational resources, high-priced communities, clusters of high socioeconomic status groups, and communities enjoying high-level education accessibility are highly consistent spatially, which is the spatial expression of educational inequality. The crucial means to promote educational equality and social mobility relies on reducing the differences in educational quality between schools and promoting reform of the school district system.

The education system plays an important role in promoting social equality. A good education system can make up for disadvantages in individuals' family background and ability endowments. It will in turn allow the rational allocation of educational resources and alleviate educational inequality caused by differences in economic and social status [60]. It turns out that countries where socioeconomic inequality between families is similar may have varying degrees of social disparities in educational accessibility. Wide gaps in income inequality exist both in New Zealand and Japan, but there is much greater educational equality in the former than the latter [61]. The same is true for Belgium and Finland, where income inequality is moderate but educational inequality varies dramatically [62]. Therefore, designing and implementing a rational education policy is the key to promoting educational equity.

The "nearby schooling" policy is an active exploration of Chinese governments. It restricts school choice and weakens the impact of family economic status on the acquisition of educational opportunities. Still, we have to admit that although nonselective schools is the common ground shared by more equal countries (such as East Asian and Nordic countries) [62], the unignorable differences in educational resources and the rapid development of the commercial housing market in China have limited this policy and even had a negative impact. Because of the intensification of the educational resources differentiation and social spatial heterogeneity, the school district system failed to reach its goal in creating a spatial balance of educational resources and equality between groups. The research results supplement the mechanism of educational equity under special circumstances, namely, the school district system, and further demonstrate the importance of education policies that promote educational equality.

It is hardly possible to achieve the equal utilization of high-quality educational resources in cities overnight, and educational equality requires long-term efforts of the government, education departments, and academia. The next step in the research on the allocation of urban educational resources should focus on how to adopt feasible policy measures and implementation paths to promote the optimization, restoration, reform, and innovation of the school district system, continuously reduce the difference in the quality of education between regions and schools, and achieve spatial balance of education quality and the social equity of educational opportunities to the maximum. Measures such as group school-running, strong schools leading weak schools, grand school district system (multischool planning), interschool mobility of excellent teachers, and tilting of education funds towards weaker schools should be actively explored to promote the full development of urban education so that the goal of social equity and spatial justice can be realized one day.

\section{Data Availability}

Data for this work are available upon request from the corresponding author.

\section{Conflicts of Interest}

The authors declare that there are no conflicts of interest regarding the publication of this paper. 


\section{Acknowledgments}

This work was supported by the National Natural Science Foundation of China (41771184).

\section{References}

[1] J. Golley and S. T. Kong, "Inequality in intergenerational mobility of education in China," China and World Economy, vol. 21, no. 2, pp. 15-37, 2013.

[2] Y. Chen and S. Feng, "Access to public schools and the education of migrant children in China," China Economic Review, vol. 26, pp. 75-88, 2013.

[3] C. Harmon, H. Oosterbeek, and I. Walker, "The returns to education: microeconomics," Journal of Economic Surveys, vol. 17, no. 2, pp. 115-156, 2003.

[4] I. Gordon and V. Monastiriotis, "Education, location, education: a spatial analysis of English secondary school public examination results," Urban Studies, vol. 44, no. 7, pp. 1203-1228, 2007.

[5] Q. Wu, X. Zhang, and P. Waley, "When Neil Smith met Pierre Bourdieu in Nanjing, China: bringing cultural capital into rent gap theory," Housing Studies, vol. 32, no. 5, pp. 659-677, 2017.

[6] S. R. Lucas, "Effectively maintained inequality: education transitions, track mobility, and social background effects," American Journal of Sociology, vol. 106, no. 6, pp. 1642-1690, 2001.

[7] W. Boterman, S. Musterd, C. Pacchi, and C. Ranci, "School segregation in contemporary cities: socio-spatial dynamics, institutional context and urban outcomes," Urban Studies, vol. 56, no. 15, pp. 3055-3073, 2019.

[8] M. Oberti, "Social and school differentiation in urban space: inequalities and local configurations," Environment and Planning A: Economy and Space, vol. 39, no. 1, pp. 208-227, 2007.

[9] W. G. Hansen, "How accessibility shapes land use," Journal of the American Institute of Planners, vol. 25, no. 2, pp. 73-76, 1959.

[10] M. Oloko-oba, O. Akintunde, A. T. Alaga et al., “A geospatial approach to evaluation of accessibility to government primary schools in Ilorin west local government area, Kwara state, Nigeria," European International Journal of Science and Technology, vol. 4, pp. 96-107, 2015.

[11] S. Yin, X. Hu, Z. Ma, and W. Song, "Spatial and temporal effects of housing price in urban school districts based on education equity: a case study of public pimary school in the main urban area of nanjing," Economic Geography, vol. 39, no. 9, pp. 82-93, 2019.

[12] S. Williams and F. Wang, "Disparities in accessibility of public high schools, in metropolitan Baton Rouge, Louisiana 1990-2010," Urban Geography, vol. 35, no. 7, pp. 1066-1083, 2014.

[13] N. Page, M. Langford, and G. Higgs, "Measuring spatial accessibility to services within indices of multiple deprivation: implications of applying an enhanced two-step floating catchment area (E2SFCA) approach," Applied Spatial Analysis and Policy, vol. 12, no. 2, pp. 321-348, 2019.

[14] T. Pengfei, L. Jing, and G. Chen, "Spatial accessibility analysis of primary schools at the county level based on the improved potential model: a case study of Xiantao city, Hubei province," Progress in Geography, vol. 36, no. 6, pp. 697-708, 2017.

[15] H.-M. Kim and M.-P. Kwan, "Space-time accessibility measures: a geocomputational algorithm with a focus on the feasible opportunity set and possible activity duration," Journal of Geographical Systems, vol. 5, no. 1, pp. 71-91, 2003.

[16] R. Wiśniewski, M. Stępniak, and B. Szejgiec-Kolenda, "Accessibility of public services in the age of ageing and shrinking population: are regions following trends," Geografiska Annaler: Series B, Human Geography, vol. 103, no. 1, pp. 55-74, 2021.

[17] E. Talen, "School, community, and spatial equity: an empirical investigation of access to elementary schools in West Virginia," Annals of the Association of American Geographers, vol. 91, no. 3, pp. 465-486, 2001.

[18] H. Wen, Y. Xiao, E. C. M. Hui, and L. Zhang, "Education quality, accessibility, and housing price: does spatial heterogeneity exist in education capitalization?" Habitat International, vol. 78, pp. 68-82, 2018.

[19] A. I. Moreno-Monroy, R. Lovelace, and F. R. Ramos, "Public transport and school location impacts on educational inequalities: insights from São Paulo," Journal of Transport Geography, vol. 67, pp. 110-118, 2018.

[20] Y. Jiang, B. Li, and R. Zhao, "An allocation scheme of students based on IPM under the nearby enrollment policy," in Proceedings of the 2019 10th International Conference on Information Technology in Medicine and Education (ITME), pp. 260-264, Qingdao, China, 2019.

[21] Y. Xu, W. Song, and C. Liu, "Social-spatial accessibility to urban educational resources under the school district system: a case study of public primary schools in nanjing, China," Sustainability, vol. 10, no. 7, p. 2305, 2018.

[22] L. Stiefel, R. Berne, P. Iatarola, and N. Fruchter, "High school size: effects on budgets and performance in New York city," Educational Evaluation and Policy Analysis, vol. 22, no. 1, pp. 27-39, 2000.

[23] J. Hennebry, J. McLaughlin, and K. Preibisch, "Out of the loop: (In) access to health care for migrant workers in Canada," Journal of International Migration and Integration, vol. 17, 2015.

[24] K. R. Ihlanfeldt and D. L. Sjoquist, "Job accessibility and racial differences in youth employment rates," The American Economic Review, vol. 80, no. 1, pp. 267-276, 1990.

[25] S. Farber, M. Z. Morang, and M. J. Widener, "Temporal variability in transit-based accessibility to supermarkets," Applied Geography, vol. 53, pp. 149-159, 2014.

[26] J. Merrell, F. Kinsella, F. Murphy, S. Philpin, and A. Ali, "Accessibility and equity of health and social care services: exploring the views and experiences of Bangladeshi carers in South Wales, UK," Health and Social Care in the Community, vol. 14, no. 3, pp. 197-205, 2006.

[27] J. Wolch, J. Wilson, and J. Fehrenbach, "Parks and park funding in Los Angeles: an equity-mapping analysis," Urban Geography, vol. 26, no. 1, pp. 4-35, 2013.

[28] R. M. Fernandez, "Race, space, and job accessibility: evidence from a plant relocation," Economic Geography, vol. 70, no. 4, pp. 390-416, 1994.

[29] S. Pinch, Cities and Services, Routledge \& Kegan Paul, London, UK, 1985.

[30] L. K. Snow, "Economic development breaks the mold: community-building, place-targeting, and empowerment zones," Economic Development Quarterly, vol. 9, no. 2, pp. 185-198, 1995.

[31] J. Kuyvenhoven and W. R. Boterman, "Neighbourhood and school effects on educational inequalities in the transition from primary to secondary education in Amsterdam," Urban Studies, Article ID 0042098020959011, 2020. 
[32] A. L. Mabogunje, The Development Process: A Spatial Perspective, Holmes \& Meier, London, UK, 1980.

[33] W. Hu and R. Wang, "Segregation in urban education: evidence from public schools in Shanghai, China," Cities, vol. 87, pp. 106-113, 2019.

[34] J. R. Logan, E. Minca, and S. Adar, "The geography of inequality," Sociology of Education, vol. 85, no. 3, pp. 287-301, 2012.

[35] D. Satz, "Unequal chances: race, class and schooling," Theory and Research in Education, vol. 10, no. 2, pp. 155-170, 2012.

[36] Q. Wu, X. Zhang, and P. Waley, "Jiaoyufication: when gentrification goes to school in the Chinese inner city," Urban Studies, vol. 53, no. 16, pp. 3510-3526, 2016.

[37] J. Petrie, J. Jerry, and H. Craig, Consolidation of Schools and Districts: What the Research Says and What it Means, National Education Policy Center, Boulder, CO, USA, 2011.

[38] S. Yin, Z. Ma, W. Song, and C. Liu, "Spatial justice of a Chinese metropolis: a perspective on housing price-to-income ratios in nanjing, China," Sustainability, vol. 11, no. 6, p. 1808, 2019.

[39] C. M. Tiebout, “A pure theory of local expenditures," Journal of Political Economy, vol. 64, no. 5, pp. 416-424, 1956.

[40] C. Liu and W. Song, "Perspectives of socio-spatial differentiation from soaring housing prices: a case study in nanjing, China," Sustainability, vol. 11, no. 9, p. 2627, 2019.

[41] D. Leech and E. Campos, "Is comprehensive education really free?: a case-study of the effects of secondary school admissions policies on house prices in one local area," Journal of the Royal Statistical Society: Series A, vol. 166, no. 1, pp. 135-154, 2003.

[42] K. Burger, "The socio-spatial dimension of educational inequality: a comparative European analysis," Studies In Educational Evaluation, vol. 62, pp. 171-186, 2019.

[43] Y. S. Lee, "School districting and the origins of residential land price inequality," Journal of Housing Economics, vol. 28, pp. 1-17, 2015.

[44] S. Machin and K. G. Salvanes, "Valuing school quality via a school choice reform," The Scandinavian Journal of Economics, vol. 118, no. 1, pp. 3-24, 2016.

[45] S. Zheng, W. Hu, and R. Wang, "How much is a good school worth in Beijing? Identifying price premium with paired resale and rental data," The Journal of Real Estate Finance and Economics, vol. 53, no. 2, pp. 184-199, 2016.

[46] H. Wen, X. Bu, and Z. Qin, "Spatial effect of lake landscape on housing price: a case study of the West Lake in Hangzhou, China," Habitat International, vol. 44, pp. 31-40, 2014.

[47] D. M. Brasington and D. Hite, "School choice and perceived school quality," Economics Letters, vol. 116, no. 3, pp. 451-453, 2012.

[48] R. Jacobsen, J. W. Snyder, and A. Saultz, "Informing or shaping public opinion? The influence of school accountability data format on public perceptions of school quality," American Journal of Education, vol. 121, no. 1, pp. 1-27, 2014.

[49] M.-P. Kwan, "Space-time and integral measures of individual accessibility: a comparative analysis using a point-based framework," Geographical Analysis, vol. 30, no. 3, pp. 191-216, 1998.

[50] X. Zhao, Q. Zheng, X. Liu, and M. Jin, "Study on the planning and allocation of urban park green space based on 2SFCA improved model-A case study of Futian district, Shenzhen," Chinese Landscape Architecture, vol. 34, no. S2, pp. 95-99, 2018.
[51] Notice on Carrying out the Supervision and Evaluation Work of Modern Schools in Zhejiang Province, http://jyt.zj.gov.cn/ art/2020/4/14/art_1532973_42574733.html.

[52] J. S. Coleman, "Equality of educational opportunity," Equity \& Excellence in Education, vol. 6, no. 5, pp. 19-28, 1968.

[53] L. Anselin, "Local indicators of spatial association-LISA," Geographical Analysis, vol. 27, no. 2, pp. 93-115, 1995.

[54] Y. Xiao, Z. Wang, Z. Li, and Z. Tang, "An assessment of urban park access in Shanghai-implications for the social equity in urban China," Landscape and Urban Planning, vol. 157, pp. 383-393, 2017.

[55] S. NBo, China City Statistical Yearbook, China Statistics Press, Beijing, China, 2019.

[56] H. Qinshi, W. Song, L. Liu et al., "Exploring residential heterogeneity through multiscalar lens: a case study of Hangzhou, China," Complexity, vol. 2021, Article ID 3798183, 12 pages, 2021.

[57] K. Yang Hansen and J.-E. Gustafsson, "Identifying the key source of deteriorating educational equity in Sweden between 1998 and 2014," International Journal of Educational Research, vol. 93, pp. 79-90, 2019.

[58] W. Song, N. Mao, P. Chen, Y. Yuan, and Y. Wang, "Coupling mechanism and spatial-temporal pattern of residential differentiation from the perspective of housing prices: a case study of Nanjing," Dili Xuebao/Acta Geographica Sinica, vol. 72, pp. 589-602, 2017.

[59] J. Östh, E. Andersson, and B. Malmberg, "School choice and increasing performance difference: a counterfactual approach," Urban Studies, vol. 50, no. 2, pp. 407-425, 2013.

[60] M. Liao and S. Hua, "Educational inequality analysis: international comparison," International Journal of Business and Social Science, vol. 2, no. 16, pp. 88-93, 2011.

[61] R. Nash, "Inequality/difference in New Zealand education: social reproduction and the cognitive habitus," International Studies in Sociology of Education, vol. 13, no. 2, pp. 171-194, 2003.

[62] M. Duru-Bellat, "Social inequality and schooling," in International Encyclopedia of the Social \& Behavioral Sciences, J. D. Wright, Ed., pp. 325-330, Elsevier, Oxford, UK, 2nd edition, 2015. 